\title{
Long-term survival and health-related quality of life in patients with severe acute respiratory distress syndrome and veno-venous extracorporeal membrane oxygenation support
}

\author{
Jonathan Rilinger ${ }^{1,2^{*}+} \mathbb{0}$, Klara Krötzsch ${ }^{1,2+}$, Xavier Bemtgen ${ }^{1,2}$, Markus Jäckel ${ }^{1,2}$, Viviane Zotzmann ${ }^{1,2}$,

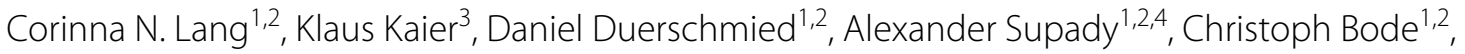 \\ Dawid L. Staudacher ${ }^{1,2}$ and Tobias Wengenmayer ${ }^{1,2}$
}

\begin{abstract}
Background: There is limited information about the long-term outcome of patients suffering from acute respiratory distress syndrome (ARDS) supported with veno-venous extracorporeal membrane oxygenation (VV ECMO). Most studies focused on short- to mid-term follow-up. We aimed to investigate long-term survival and health-related quality of life (HRQL) in these patients.

Methods: We report retrospective data from a single-centre registry of patients with severe ARDS treated with VV ECMO at the Interdisciplinary Medical Intensive Care Unit at the Medical Centre, University of Freiburg, Germany, between 10/2010 and 06/2019. Follow-up data of all patients that survived the index hospitalisation were collected by telephone interviews from 02/2020 till 09/2020. Long-term survival, HRQL (Short-Form Health Survey-36 (SF-36), St. Georges Respiratory Questionnaire (SGRQ), Hospital Anxiety and Depression Scale (HADS)) and the return to work rate were documented.

Results: In total, 289 patients were treated with VV ECMO during the study period (median age 55 years, $67 \%$ males, hospital survival 45\%). After a median duration of 3.9 years, follow-up assessment was complete in 94 of 129 hospital survivors (73\%). Fifty-three patients completed the HRQL assessment. Hospital survivors showed a high 6- and 12-month survival rate (89\% and $85 \%$, respectively). Estimated survival rate of those discharged alive from ICU was 68.5\% (95\%-Cl 56.9-80.1\%) after 9.7 years. These patients reported high levels of HRQL (median SF-36 total score 73) and only few pulmonary (median SGRQ total score 19) and mental limitations (median HAD-D score 2 and HAD-A score 3). In total, $80 \%$ of the patients were able to resume employment.
\end{abstract}

Conclusion: This analysis of WV ECMO patients showed favourable long-term survival and high levels of HRQL suggesting promising prospects for W ECMO survivors.

*Correspondence: jonathan.rilinger@universitaets-herzzentrum.de

${ }^{\dagger}$ Jonathan Rilinger and Klara Krötzsch share the first authorship

${ }^{1}$ Department of Medicine III (Interdisciplinary Medical Intensive Care),

Medical Center, Faculty of Medicine, University of Freiburg, Freiburg,

Germany

Full list of author information is available at the end of the article

(c) The Author(s) 2021. Open Access This article is licensed under a Creative Commons Attribution 4.0 International License, which permits use, sharing, adaptation, distribution and reproduction in any medium or format, as long as you give appropriate credit to the original author(s) and the source, provide a link to the Creative Commons licence, and indicate if changes were made. The images or other third party material in this article are included in the article's Creative Commons licence, unless indicated otherwise in a credit line to the material. If material is not included in the article's Creative Commons licence and your intended use is not permitted by statutory regulation or exceeds the permitted use, you will need to obtain permission directly from the copyright holder. To view a copy of this licence, visit http://creativecommons.org/licenses/by/4.0/. The Creative Commons Public Domain Dedication waiver (http://creativeco mmons.org/publicdomain/zero/1.0/) applies to the data made available in this article, unless otherwise stated in a credit line to the data. 
Keywords: ECMO, Extracorporeal membrane oxygenation, Acute respiratory distress syndrome, Outcome, Survival, Long-term, Quality of life

\section{Graphical Abstract}

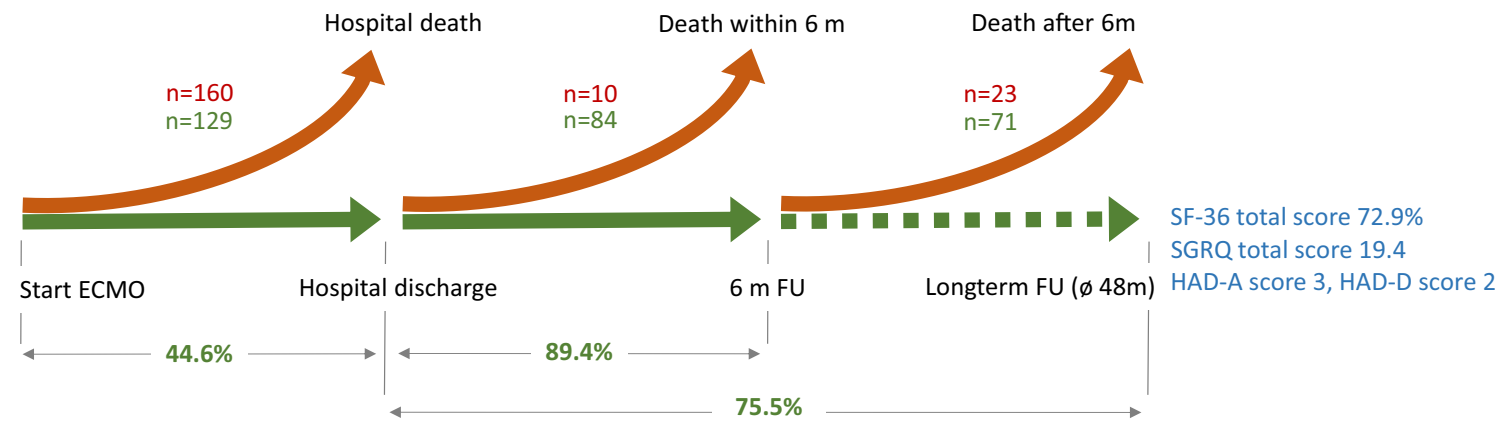

Long-term outcome of patients after veno-venous extracorporeal membrane oxygenation for acute respiratory distress syndrome

Survival rates related to each time period are shown below the timeline. Long-term follow-up was successful for 94 of 129 survivors of the initial hospital stay (72.8\%). In addition, median health-related quality of life (HRQL) scores after a 48-month long-term follow-up are presented. ECMO: extracorporeal membrane oxygenation; FU: Follow-up.

\section{Background}

Patients with severe acute respiratory distress syndrome (ARDS) may benefit from veno-venous extracorporeal membrane oxygenation (VV ECMO) support [1-3]. A substantial increase in the use of ECMO support has been recorded over the recent years [4]. Nevertheless, the mortality of these patients remains very high [2]. In addition, patients suffer from complications as a result of their underlying disease or as a direct consequence of ECMO support, such as secondary infections, bleedings, thromboses and embolisms [5, 6]. Moreover, patients surviving complex intensive care treatment including severe ARDS therapy and ECMO support are often severely compromised even after discharge and at risk to subsequently die in the further course [7].

It is difficult to predict long-term survival of individual patients. Future quality of life is often of major interest for the patients, relatives and ICU teams. The resource-intensive and extended course of these patients, often prone to serious complications, may lead to a high level of emotionality within the treatment teams with a potential impact on therapy decisions. More evidence about long-term survival and longterm quality of life would therefore be of great value for appropriate therapy management. However, most VV ECMO outcome studies only focus on hospital survival or a short- to mid-term outcome after 6 or 12 months, respectively [7-11].

We performed an analysis of long-term survival, long-term health-related quality of life (HRQL) and the rate of return to work with an extended follow-up period in ARDS patients supported with VV ECMO. Furthermore, we analysed factors associated with hospital and mid-term survival.

\section{Methods \\ Study population}

We report retrospective data from a single-centre registry of adult patients with severe ARDS according to the Berlin definition (Horowitz index $<100 \mathrm{mmHg}$ ) [12] supported with VV ECMO. VV ECMO was initiated in cases of severe hypoxic respiratory failure or hypercapnia despite invasive mechanical ventilation as suggested by ELSO guidelines [13].

All patients treated at the Interdisciplinary Medical Intensive Care Unit at the Medical Centre, University of Freiburg, Germany, from October 2010 through June 2019 were registered. Follow-up data of all patients surviving the index hospitalisation were collected by standardized telephone interviews from February 2020 through September 2020. We followed a systematic approach for contacting the patients using the last available registration address, the patients telephone numbers, the contact information (postal and telephone) of relatives or caregivers, and the patient primary care physician. All patients who were interviewed by telephone provided written informed consent to participate in the study. The study was approved by the University of Freiburg Ethics Committee (EK-Freiburg 553/19).

\section{Study endpoints and definitions}

The primary endpoint of this study was long-term survival (Kaplan-Meier survival estimation) after hospital 
discharge. Secondary endpoints were 6- and 12-month survival rates as well as HRQL at the time of the followup (The Short-Form Health Survey-36 (SF-36) [14], St. Georges Respiratory Questionnaire (SGRQ) [15] and Hospital Anxiety and Depression Scale (HADS) [16]). In addition, predictors for hospital survival and 6-month survival of initial hospital survivors (landmark analysis) were investigated. The HRQL was compared with a sample of the German general population [17, 18]. The results of the respiratory questionnaire were compared with a chronic obstructive pulmonary disease (COPD) reference cohort [19] as well as with a sample of a European general population (IBERPOC, Spain) [20] (in absence of a representative German sample). In addition, we compared our results with the findings from previous ECMO (CESAR [7] and PRESERVE [8] study) and ARDS cohorts (meta-analysis of Dowdy et al. [21] and Herridge et al. [22]). Finally, we investigated the influence of the followup time and the duration of ECMO support on HRQL.

Successful ECMO weaning was defined as being free from ECMO support and alive for at least $48 \mathrm{~h}$ after decannulation. Unsuccessful weaning was defined as the inability to explant the ECMO device because of persistent respiratory failure or death during ECMO support or the need for re-cannulation within $48 \mathrm{~h}$.

To evaluate the patients' disease severity, RESP [23], SOFA [24] and APACHE-II [25] scores as well as the p/Fratio $(\mathrm{paO} 2 / \mathrm{FiO} 2)$ prior to cannulation were analysed.

Immunosuppression was defined as: immunosuppression in case of oncological malignancies (including haematooncological malignancies and active solid tumours), caused by the disease itself or by related therapy (chemotherapy or haematopoietic stem cell transplantation (HSCT) 12 months prior to ECMO support); immunosuppression in patients after solid organ transplantation; patients with autoimmune diseases and immunosuppressive therapies (cut-off for cortisone: $\geq 10 \mathrm{mg}$ prednisolone equivalent) and patients with immunosuppression caused by HIV.

Furthermore, pulmonary pathogen spectrum ascertained by broncho-alveolar lavage and tracheal secretions was investigated. Assignment to pulmonary pathogens was based on concordance of microbiological findings with clinical signs of infection.

\section{ECMO centre and ECMO management}

Our centre provides a 24/7 ECMO service and is localized joined to a 30-bed medical intensive care unit and part of a tertiary hospital. Typical numbers for veno-arterial and veno-venous cannulation are 65 and 35 per year, respectively.

In our institution, for mechanical ventilation (MV) in severe ARDS generally biphasic positive airway pressure (bilevel ventilation) is used. VV ECMO support was implemented in case of severe but potentially reversible respiratory failure, when lung-protective MV resulted in hypoxemia or hypercapnia following established criteria [26]. To date, lung-protective $M V$ was defined as positive end expiratory pressure (PEEP) $\leq 15 \mathrm{cmH}_{2} \mathrm{O}$, plateau pressure $\leq 30 \mathrm{cmH}_{2} \mathrm{O}$, driving pressure $\leq 15 \mathrm{cmH}_{2} \mathrm{O}$ and $\mathrm{FiO}_{2} \leq 50 \%$. The management of vasopressors and fluid therapy was driven by clinical judgement of the ECMO experienced intensivist in charge and has been reported earlier [27]. Treatment algorithms and standard operating procedures were subject to optimizations during the observational period, reflecting current state-of-the-art recommendations and scientific knowledge. In particular, patient selection was adjusted with regard to comorbidities, so that patients with immunosuppression are only treated with ECMO after very careful evaluation and patients with lung fibrosis (with a few exceptions) are no longer supported with ECMO.

After initiation of VV ECMO, invasiveness of MV was reduced and ECMO flow was adjusted aiming for a peripheral oxygen saturation of $85-90 \%$ and partial pressure arterial oxygen of approximately $60 \mathrm{mmHg}$. Typical ventilator settings were: PEEP $15 \mathrm{cmH}_{2} \mathrm{O}$, plateau pressure $25 \mathrm{cmH}_{2} \mathrm{O}, \mathrm{FiO}_{2} 50 \%$, respiratory rate $10 / \mathrm{min}$. Details on ventilator management and prone positioning procedures have been described earlier [28]. Additional information about ECMO management is available in Additional file 1.

\section{Statistical analysis}

Continuous variables are presented as median and interquartile range (IQR), categorical variables as numbers and percentages. Mann-Whitney $U$ test was used for analysis of continuous variables, Pearson's Chi-squared test or Fisher's exact test for categorical variables. Logistic regression analysis using forward selection with a threshold of $\mathrm{p}<0.05$ of all clinical characteristics (excluding survival prediction scores) was performed for predictors of hospital survival and 6-month survival. Results are given as odds ratio [(OR), 95\% confidence interval (CI)], and a $\mathrm{p}$ value of $\leq 0.05$ was considered statistically significant. Primary endpoint (long-term survival after hospital discharge) was analysed using the KaplanMeier method. Median follow-up time was calculated as the simple median time from discharge to last follow-up point. Statistical calculations were performed using IBM SPSS statistics 25.0 (Armonk, NY: IBM Corp, 2017). Survival analysis was conducted in R (R Core Team, 2014), and figures were produced using the package ggplot2 (Wickham, 2009) and GraphPad Prism 9 (San Diego, California USA, 2020). 
Table 1 Clinical characteristics and their association to hospital survival

\begin{tabular}{|c|c|c|c|c|}
\hline & \multirow{2}{*}{$\begin{array}{l}\text { All } \\
(n=289)\end{array}$} & \multicolumn{2}{|c|}{ Status after index hospitalisation } & \multirow[t]{2}{*}{$p$ value } \\
\hline & & $\begin{array}{l}\text { Alive } \\
(n=129,44.6 \%)\end{array}$ & $\begin{array}{l}\text { Dead } \\
(n=160,55.4 \%)\end{array}$ & \\
\hline \multicolumn{5}{|l|}{ Demographics } \\
\hline Age (y) & $55(43-64)$ & $53(41.5-59.5)$ & $56(45-66.8)$ & 0.027 \\
\hline Sex (male) & $194(67.1 \%)$ & $89(69 \%)$ & $105(65.6 \%)$ & 0.545 \\
\hline $\mathrm{BMI}\left(\mathrm{kg} / \mathrm{m}^{2}\right)$ & $24.5(23.4-29.3)$ & $24.5(22.9-30.2)$ & $24.4(23.5-27.8)$ & 0.610 \\
\hline $\begin{array}{l}\text { Underlying pulmonary } \\
\text { disease }\end{array}$ & $87(30.1 \%)$ & $32(24.8 \%)$ & $55(34.4 \%)$ & 0.078 \\
\hline COPD & $25(8.7 \%)$ & $11(8.5 \%)$ & $14(8.8 \%)$ & 0.947 \\
\hline Asthma & $16(5.5 \%)$ & $7(5.4 \%)$ & $9(5.6 \%)$ & 0.941 \\
\hline Lung fibrosis & $26(9 \%)$ & $2(1.6 \%)$ & $24(15 \%)$ & $<0.001$ \\
\hline Cystic fibrosis & $7(2.4 \%)$ & $1(0.8 \%)$ & $6(3.8 \%)$ & 0.102 \\
\hline LTOT & $14(4.8 \%)$ & $3(2.3 \%)$ & $11(6.9 \%)$ & 0.073 \\
\hline $\begin{array}{l}\text { Pulmonary hyperten- } \\
\text { sion }\end{array}$ & $8(2.8 \%)$ & $1(0.8 \%)$ & $7(4.4 \%)$ & 0.064 \\
\hline \multicolumn{5}{|l|}{ Comorbidities } \\
\hline Nicotine abuse & 98 (33.9\%) & $50(38.8 \%)$ & 48 (30\%) & 0.118 \\
\hline Hypertension & $99(34.3 \%)$ & $49(38 \%)$ & $50(31.3 \%)$ & 0.230 \\
\hline Diabetes mellitus & $39(13.5 \%)$ & $17(13.2 \%)$ & $22(13.8 \%)$ & 0.888 \\
\hline CAD & $36(12.5 \%)$ & $13(10.1 \%)$ & $23(14.4 \%)$ & 0.271 \\
\hline Chronic renal failure & $21(7.3 \%)$ & $8(6.2 \%)$ & $13(8.1 \%)$ & 0.531 \\
\hline Chronic haemodialysis & $2(9.1 \%)$ & $1(12.5 \%)$ & $1(7.1 \%)$ & 0.674 \\
\hline Liver cirrhosis & $22(7.6 \%)$ & $4(3.1 \%)$ & $18(11.3 \%)$ & 0.009 \\
\hline Immunosuppression & $89(30.8 \%)$ & $24(18.6 \%)$ & $65(40.6 \%)$ & $<0.001$ \\
\hline \multicolumn{5}{|l|}{ Oxygenation pre-ECMO } \\
\hline $\mathrm{FiO}_{2}(\%)$ & $1(0.8-1)$ & $1(0.8-1)$ & $1(0.8-1)$ & 0.271 \\
\hline $\begin{array}{l}\text { Horowitz index } \\
(\mathrm{mmHg})\end{array}$ & $72.5(60.5-98.8)$ & $77.1(62.1-107)$ & $70(59.3-95.7)$ & 0.256 \\
\hline $\mathrm{D}(\mathrm{A}-\mathrm{a}) \mathrm{O}_{2}(\mathrm{mmHg})$ & $556(422.8-596.8)$ & $550(385.5-591.8)$ & $570(442.3-598)$ & 0.115 \\
\hline $\begin{array}{l}\text { Duration of MV before } \\
\text { ECMO (d) }\end{array}$ & $1.2(0.3-3.5)$ & $1.1(0.2-3)$ & $1.3(0.3-5.3)$ & 0.341 \\
\hline$<2 d$ & $161(59.6 \%)$ & $76(62.3 \%)$ & $85(57.4 \%)$ & 0.418 \\
\hline $2-7 d$ & $69(25.6 \%)$ & $30(24.6 \%)$ & 39 (26.4\%) & 0.741 \\
\hline$>7 d$ & $40(14.8 \%)$ & $16(13.1 \%)$ & $24(16.2 \%)$ & 0.475 \\
\hline Acute renal failure & $95(32.9 \%)$ & $46(35.7 \%)$ & $49(30.6 \%)$ & 0.365 \\
\hline \multicolumn{5}{|l|}{ Scores } \\
\hline SOFA score & $13(10-15)$ & $12(10-15)$ & $13(10-16)$ & 0.439 \\
\hline APACHE-II score & $26(20.5-32)$ & $25(19-31)$ & $27(22-33)$ & 0.022 \\
\hline RESP score & $1(-2-3)$ & $2(-0.5-4)$ & $1(-2-3)$ & 0.006 \\
\hline \multicolumn{5}{|l|}{ Causes of ARDS } \\
\hline Pneumonia & $206(71.3 \%)$ & $89(69 \%)$ & $117(73.1 \%)$ & 0.440 \\
\hline Aspiration & $25(8.7 \%)$ & $10(7.8 \%)$ & $15(9.4 \%)$ & 0.626 \\
\hline Other injuries & $58(20.1 \%)$ & $30(23.3 \%)$ & $28(17.5 \%)$ & 0.225 \\
\hline \multicolumn{5}{|c|}{ Pulmonary pathogen spectrum } \\
\hline Bacterial & $120(41.5 \%)$ & $67(51.9 \%)$ & $53(33.1 \%)$ & 0.001 \\
\hline Viral & $91(31.5 \%)$ & $44(34.1 \%)$ & $47(29.4 \%)$ & 0.389 \\
\hline Fungal & $56(19.4 \%)$ & $16(12.4 \%)$ & $40(25 \%)$ & 0.007 \\
\hline Pneumocystis jirovecii & $19(6.6 \%)$ & $4(3.1 \%)$ & $15(9.4 \%)$ & 0.032 \\
\hline \multicolumn{5}{|c|}{ Procedural characteristics and outcome } \\
\hline ICU length of stay (d) & $13.5(9-23.5)$ & $17.9(11.7-32.8)$ & $11.1(5.5-18.9)$ & $<0.001$ \\
\hline
\end{tabular}


Table 1 (continued)

\begin{tabular}{|c|c|c|c|c|}
\hline & \multirow{2}{*}{$\begin{array}{l}\text { All } \\
(n=289)\end{array}$} & \multicolumn{2}{|c|}{ Status after index hospitalisation } & \multirow[t]{2}{*}{$p$ value } \\
\hline & & $\begin{array}{l}\text { Alive } \\
(n=129,44.6 \%)\end{array}$ & $\begin{array}{l}\text { Dead } \\
(n=160,55.4 \%)\end{array}$ & \\
\hline ECMO duration (d) & $6.7(3.9-12.1)$ & $6.6(4.4-11.5)$ & $6.8(3.3-13.2)$ & 0.903 \\
\hline MV duration (d) & $12.5(7.6-22.4)$ & $14.5(9.5-30.2)$ & $10.9(5.3-19.4)$ & $<0.001$ \\
\hline Dual-Iumen cannula & $245(84.8 \%)$ & $115(89.1 \%)$ & $130(81.3 \%)$ & 0.063 \\
\hline Primary non-IMV ECMO & $18(6.2 \%)$ & $6(4.7 \%)$ & $12(7.5 \%)$ & 0.319 \\
\hline Tracheostomy & $111(38.4 \%)$ & $62(48.1 \%)$ & $49(30.6 \%)$ & 0.002 \\
\hline Haemodialysis & $109(37.7 \%)$ & $47(36.4 \%)$ & $62(38.8 \%)$ & 0.686 \\
\hline
\end{tabular}

$p$ values $<0.05$ are presented in bold

APACHE II score: Acute Physiology And Chronic Health Evaluation; ARDS: acute respiratory distress syndrome; BMI: body mass index; CAD: coronary artery disease; COPD: chronic obstructive pulmonary disease; ECMO: extracorporeal membrane oxygenation; $\mathrm{FiO}_{2}$ : fraction of inspired oxygen; ICU: intensive care unit; IMV: invasive mechanical ventilation; LTOT: long-term oxygen therapy; MV: mechanical ventilation; RESP score: Respiratory Extracorporeal Membrane Oxygenation Survival Prediction; SOFA score: Sequential Organ Failure Assessment

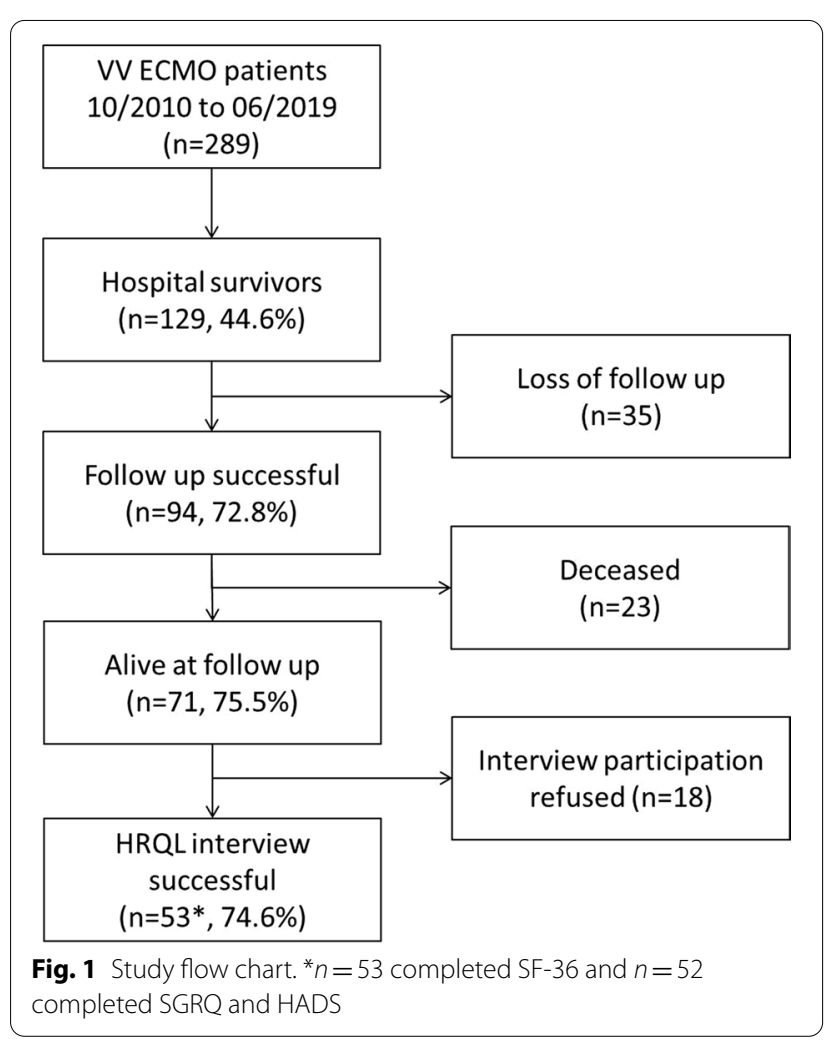

\section{Results}

\section{Patients and follow-up}

A total of 289 patients were treated with VV ECMO at our centre in the study period (median age 55 (43-64) years, $67.1 \%$ males). These patients showed a high rate of underlying pulmonary diseases (30.1\%), especially lung fibrosis (9\%), and other comorbidities like immunosuppression (31\%) and liver cirrhosis (7.6\%, Table 1). Median SOFA score was 13 (10-15), APACHE-II score
26 (20.5-32) and RESP score $1(-2-3)$ indicating a high disease severity.

Follow-up duration ranged from 1.3 to 9.7 years with a median follow-up of 3.9 (2.2-6.6) years. Follow-up was successful in 94 of 129 hospital survivors $(72.8 \%$, Fig. 1). Seventy-one (75.5\%) of these patients were alive at follow-up, and 53 patients (74.6\%) agreed to a HRQL assessment.

\section{Hospital, mid-term and long-term survival}

Weaning was successful in 153 of 289 ECMO patients (52.9\%) and 129 patients (44.6\%) survived the index hospital stay. Hospital survivors showed a high midterm survival rate with 84 of 94 patients $(89.4 \%)$ alive after 6 months and 80 of 94 patients (85.1\%) alive after 12 months, respectively. Kaplan-Meier estimation showed a survival rate of $68.5 \%$ (95\%-CI 56.9-80.1\%) 9.7 years after ECMO support (Fig. 2, Kaplan-Meier estimation of all patients is shown in Additional file 1: figure E6).

\section{Predictors for hospital and 6-month survival}

In univariate analysis age, lung fibrosis, liver cirrhosis, immunosuppression, fungal pulmonary infection were associated with increased hospital mortality, while bacterial pulmonary infection was associated with increased hospital survival (Table 1). Logistic regression analysis revealed age, lung fibrosis, liver cirrhosis, immunosuppression and bacterial pulmonary infection as independent predictors for hospital mortality and survival, respectively (Fig. 3).

In the landmark analysis of hospital survivors with successful follow-up underlying pulmonary disease, longterm oxygen therapy, a duration of MV before ECMO of more than 7 days and the duration of ECMO support itself were associated with reduced 6-month survival 


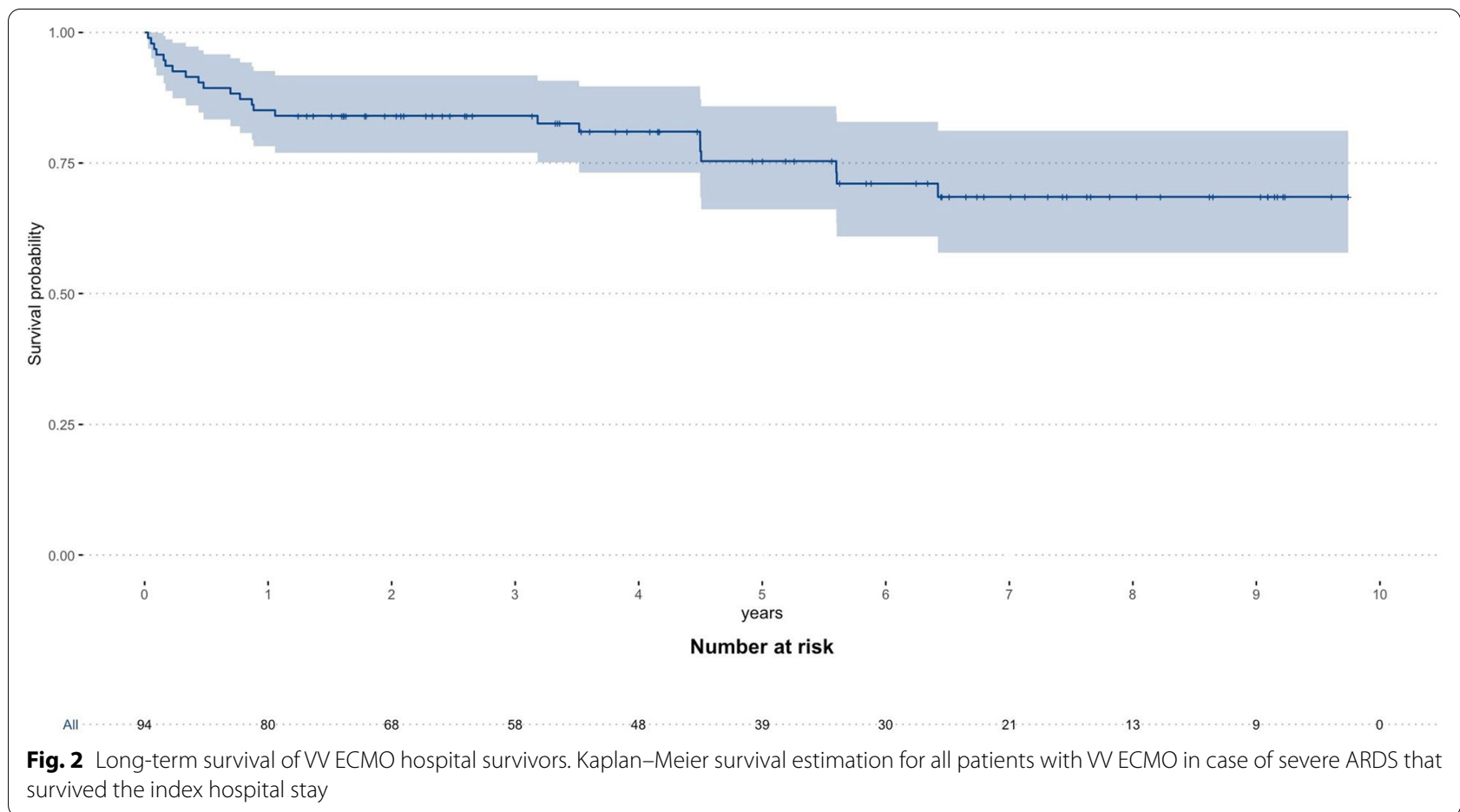

(Additional file 1: Table E1). In logistic regression analysis only the duration of ECMO support was an independent predictor for 6-month mortality (odds ratio: 0.66 (95\%-CI 0.01-0.91, $\mathrm{p}=0.010$ ) per week (Fig. 3).

\section{Long-term health-related quality of life}

HRQL assessment was successful for 53 patients (one patient only completed SF-36, therefore 52 patients for SGRQ and HADS assessment) and conducted 3.9 (2.26.6) years after ECMO cannulation.

A great number of these patients were working at follow-up (82\%; 61\% continued in their previous job, $21 \%$ had to change their jobs), $8 \%$ were permanently disabled, and $10 \%$ were already without work before ECMO support (Fig. 4, a).

The SF-36 showed a high total score of 72.9 (61.7-83.8), which was within the range of the German age- and sexadjusted reference cohort. Only the categories physical, role limitations, physical health and general health showed a higher level of limitations in the ECMO cohort (Fig. 4, b).

The level of anxiety (HAD-A) was comparable to the German reference cohort, and the level of depression (HAD-D) was even significantly lower in the ECMO cohort (Fig. 4, c).

Respiratory limitations (measured by the SGRQ) ranged between the limitations prevalent in the general population (IBERPOC) and those of a reference cohort of COPD patients (COSYCONECT). In every single category of the SGRQ (impacts, symptoms and activity), the patients of the ECMO cohort showed significant lower levels of limitation compared to the COPD cohort but higher levels of limitation compared to the general population (Fig. 4, d).

An association between HRQL and the time to followup after ECMO cannulation could not be demonstrated in this cohort (Additional file 1: Table E2). With the exception of the SF-36 physical role and HAD-A, there was also no association between HRQL and the duration of ECMO support (Additional file 1: Table E3).

Reference ECMO and ARDS cohorts showed comparable levels of HRQL. The SF-36 showed a slight trend in favour for the presented ECMO cohort in the total score and in the categories physical functioning, social functioning and emotional role (Additional file 1: figure E1 and E2). The results of the SGRQ and the HAD-A were comparable, while the results of the HAD-D were slightly higher in comparative groups (Additional file 1: figure E3 and E4). Moreover, there was a trend for a higher back to work rate in the presented ECMO patients compared to the reference studies (Additional file 1: figure E5).

\section{Discussion}

This analysis describes, to the best of our knowledge, the longest follow-up period of VV ECMO patients reported so far and showed a remarkable long-term survival rate as well as high levels of health-related quality of life. 


\begin{tabular}{llrr}
\hline Predictors \\
of hospital survival
\end{tabular}

Patients in this cohort were similar in age and gender distribution to previous ECMO cohorts, but had a high rate of relevant comorbidities, particularly lung fibrosis, immunosuppression and liver cirrhosis, resulting in high hospital mortality.

Patients that survived initial hospitalisation showed a very high 6-month survival of nearly $90 \%$ which is comparable to the results of the CESAR trial [7]. Moreover, these patients showed a 10-year survival rate of approximately $70 \%$.

Most analyses of survival predictors focus on a baseline analysis with respect to hospital survival or 6-month survival. To increase our understanding of factors that may affect post-discharge survival, we also performed a landmark analysis of hospital survivors. Predictors of hospital survival were age and severe pre-existing conditions such as lung fibrosis, liver cirrhosis, immunosuppression and pulmonary pathogen spectrum. These are typical factors which were associated with survival in previous ECMO studies [8, 23, 29-31] as well.

Most interestingly, our landmark analysis showed that pre-existing conditions of VV ECMO patients that survived the index hospitalisation were no longer associated with the probability of long-term survival. The only independent predictor of 6-month survival was the duration of ECMO support.

Possibly, patients with severe pre-existing conditions and a poor general state of health prior to ARDS die frequently during ECMO support and patients with less severe preexisting conditions tend to survive. Therefore, these underlying diseases seem to play a minor role in the further course of the patients. In contrast, after the initial hospital 


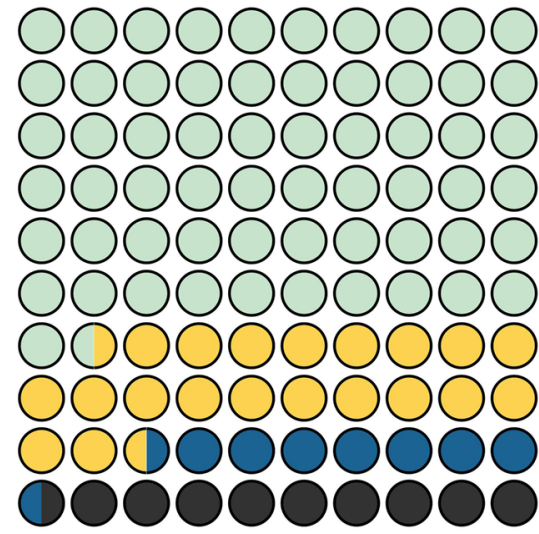

$\square 61.50 \%$ Same work

$\square 21.20 \%$ Other work

$\square 7.70 \%$ Disabled, no work

$\square 9.60 \%$ No work before

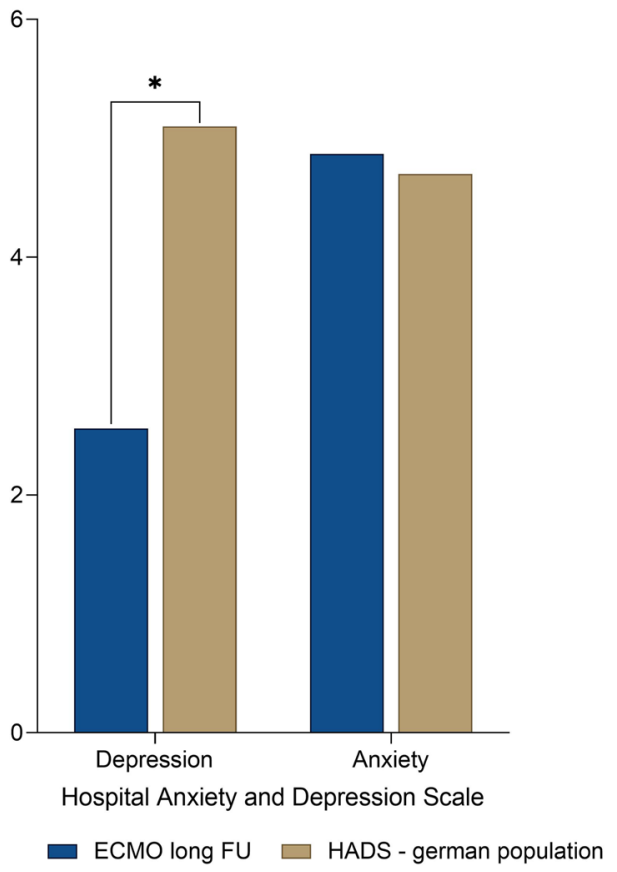

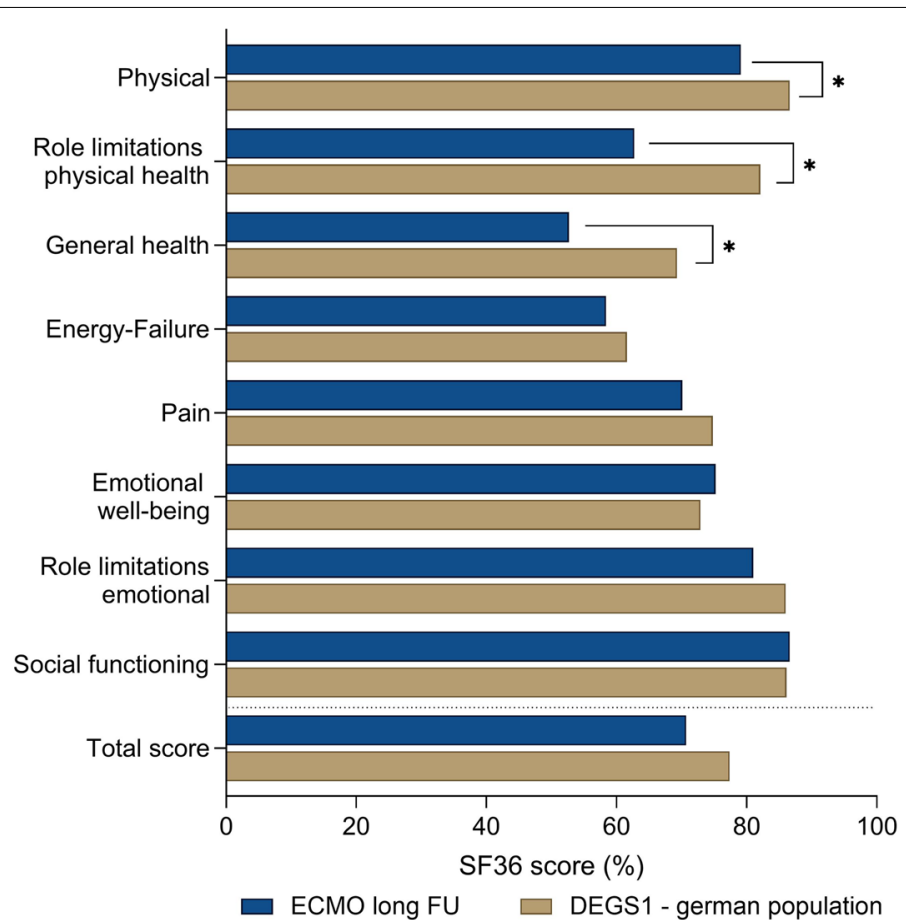

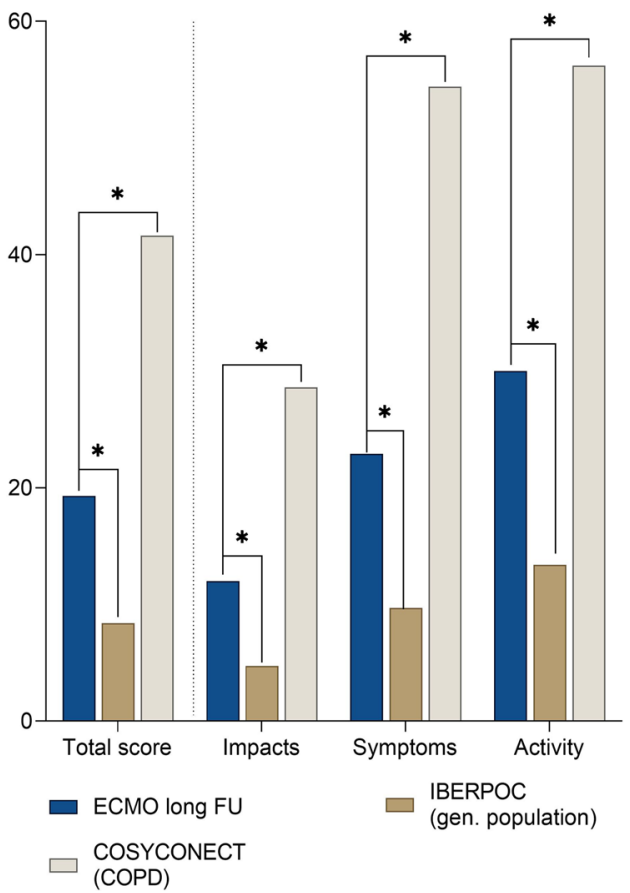

Fig. 4 Health-related quality of life in the long-term follow-up of WV ECMO survivors. A) Distribution of patients, who were able to return to work after discharge, had to change their job or were no longer able to work. B) SF-36 of WV ECMO survivors compared to German general population (DESG1) [18]. Higher scores denote better health-related quality of life. C) HAD-D and HAD-A compared to German general population (Hinz et al.) [17]. Lower scores denote lower levels of depression and anxiety. D) SGRQ compared to the German COSYCONECT population (COPD reference cohort) [19] and the Spanish IBERPOC general population [20]. Lower scores denote lower levels of pulmonary impairment. ECMO extracorporeal membrane oxygenation; $W$ veno-venous 
survival the severity and course of the ARDS, represented by the duration of the necessary ECMO support, seems to play a more significant role in mid-term prognosis.

In addition to favourable long-term survival, the HRQL of these patients was also high.

In a comprehensive analysis of the quality of life by the SF-36, low extents of restrictions were shown in comparison with the age- and sex-adjusted German general population [18]. Interestingly, the only differences with lower quality of life were detected in general health and physical limitations. There were no limitations in the realm of the emotional situation and social functioning. In line with this, a specific analysis of the mental state of these patients did not show any restrictions compared to the German population [17]. In contrast, the level of the HAD-D scale, which indicates depression, was even below the level of the general population.

The evaluation of respiratory limitations, as measured by the SGRQ, was promising as well. Only moderate limitations were observed, which were intermediate between those of the general population [20] and a large population study of COPD patients [19].

Altogether, in a median of almost 4 years after ECMO, apart from minor physical limitations and moderate pulmonary limitation, the quality of life of these individuals was very high, especially with regard to their psychological condition.

The quality of life measured in our study cohort was even better than in previous HRQL analyses of ECMO or ARDS survivors [21, 32, 33]. One hypothesis could be a correlation between the time point of the HRQL survey and the level of remaining limitations. While the CESAR trial [7] with a 6-month follow-up reported a relatively low SF-36 score, the PRESERVE study [8] with an average follow-up a of 17 months reported better SF-36 scores. A similar distribution was found for the proportion of patients that were able to return to work. However, in this study there was no correlation between the duration of follow-up and the level of HRQL. This might be due to the fact that the shortest follow-up started at 1.3 years and thus the early phase after discharge could not be assessed. To further investigate this hypothesis, a serial prospective follow-up with standardized intervals would be necessary.

In summary, these results indicate a rather good HRQL after ECMO.

The median age of the patients in this study was 55 years, and they were therefore expected to continue to work for more than 10 years. Therefore, an economic consideration of the survivors is also important. Also from this point of view, the results were very encouraging, as only $8 \%$ of the patients who were working before the ARDS developed a disability and over $60 \%$ even were able to remain in their former job. This high rate of ability to work could be a result of the overall lower physical and mental limitations compared to previous studies $[7,8,21]$.

In the here reported retrospective analysis, both survival and quality of life showed very encouraging longterm results. These results may help to strengthen the confidence of patients, relatives and ICU teams involved in the treatment of severe ARDS requiring ECMO support. In order to confirm these results and to explore changes in HRQL over time, large prospective studies with defined follow-up intervals should be conducted.

\section{Limitations}

This is a retrospective observational study, and therefore, there is a risk of selection and reporting bias, although all ECMO patients of our centre were included and the ECMO indication was based on standardized algorithms. Thus, our patients showed similar disease severity and mortality compared to previous ECMO studies. Moreover, this is a single-centre report and centre-specific processes may influence the presented results. The loss of follow-up rate is comparable to previous studies on HRQL in ECMO patients, and we therefore consider it acceptable for a retrospective analysis and a particularly long follow-up period. However, a distortion of the results due to missing data (loss of follow-up 4 years after initial hospital stay was 27\%) cannot be excluded. Moreover, one quarter of the patients did not participate in the HRQL interview. Together, due to these limitations, our findings should be considered as hypothesis-generating and should not prompt clinical decision-making.

\section{Conclusion}

This analysis of VV ECMO patients showed an encouraging long-term survival rate with a high level of health-related quality of life and thereby demonstrates a promising perspective for ECMO survivors.

\section{Abbreviations \\ APACHE II score: Acute Physiology And Chronic Health Evaluation; ARDS: Acute respiratory distress syndrome; BAL: Broncho-alveolar lavage; BMI: Body mass index; CAD: Coronary artery disease; COPD: Chronic obstructive pulmonary disease; $\mathrm{D}(\mathrm{A}-\mathrm{a}) \mathrm{O}$ 2: Alveolar-arterial gradient of oxygen concentra- tion; ECMO: Extracorporeal membrane oxygenation; $\mathrm{FiO}_{2}$ : Fraction of inspired oxygen; HRQL: Health-related quality of life; IMV: Invasive mechanical ventila- tion; ICU: Intensive care unit; LTOT: Long-term oxygen therapy; MV: Mechanical ventilation; PEEP: Positive end expiratory pressure; RESP score: Respiratory Extracorporeal Membrane Oxygenation Survival Prediction; SOFA score: Sequential Organ Failure Assessment; TS: Tracheal secretions; W: Veno-venous.}

\section{Supplementary Information}

The online version contains supplementary material available at https://doi. org/10.1186/s13054-021-03821-0.

Additional file 1: Figure E1-E5 and Table E1-E3: Long-term survival and health-related quality of life in patients with severe acute respiratory 
distress syndrome and veno-venous extracorporeal membrane oxygenation support—Online data supplement.

\section{Acknowledgements}

Not applicable.

\section{Authors' contributions}

JR and TW contributed to the conception of the study; JR, KK and TW contributed to data collection; interviews were conducted by KK; JR, KK, XB, MJ, VZ, $C N L, K K, D D, A S, C B, D L S$ and TW contributed to data analysis and interpretation; JR, KK and TW drafted the manuscript; XB, MJ, VZ, CNL, DD, AS, CB and DLS revised the manuscript for important intellectual content. All authors approved the final version of the manuscript.

\section{Funding}

Open Access funding enabled and organized by Projekt DEAL.

\section{Availability of data and materials}

The datasets used and/or analysed during the current study are available from the corresponding author on reasonable request.

\section{Declarations}

Ethics approval and consent to participate

The protocol was approved by our institution's ethical committee (EK-Freiburg 553/19).

\section{Consent for publication}

Not applicable.

\section{Competing interests}

The authors declare that they have no competing interests.

\section{Author details}

'Department of Medicine III (Interdisciplinary Medical Intensive Care), Medical Center, Faculty of Medicine, University of Freiburg, Freiburg, Germany. ${ }^{2}$ Department of Cardiology and Angiology I, Heart Center Freiburg University, Faculty of Medicine, University of Freiburg, Hugstetterstr. 55, 79106 Freiburg, Germany. ${ }^{3}$ Institute of Medical Biometry and Statistics, University Medical Center Freiburg, Faculty of Medicine, University of Freiburg, Freiburg, Germany. ${ }^{4} \mathrm{Hei}-$ delberg Institute of Global Health, University of Heidelberg, Freiburg, Germany.

Received: 23 July 2021 Accepted: 8 November 2021

Published online: 29 November 2021

\section{References}

1. Combes A, Hajage D, Capellier G, Demoule A, Lavoue S, Guervilly C, Da Silva D, Zafrani L, Tirot P, Veber B, et al. Extracorporeal membrane oxygenation for severe acute respiratory distress syndrome. N Engl J Med. 2018;378(21):1965-75.

2. Munshi L, Walkey A, Goligher E, Pham T, Uleryk EM, Fan E. Venovenous extracorporeal membrane oxygenation for acute respiratory distress syndrome: a systematic review and meta-analysis. Lancet Respir Med. 2019;7(2):163-72.

3. Combes A, Peek GJ, Hajage D, Hardy P, Abrams D, Schmidt M, Dechartres A, Elbourne D. ECMO for severe ARDS: systematic review and individual patient data meta-analysis. Intensive Care Med. 2020;46(11):2048-57.

4. Karagiannidis C, Brodie D, Strassmann S, Stoelben E, Philipp A, Bein T, Muller T, Windisch W. Extracorporeal membrane oxygenation: evolving epidemiology and mortality. Intensive Care Med. 2016;42(5):889-96.

5. Luyt CE, Brechot N, Demondion P, Jovanovic T, Hekimian G, Lebreton G, Nieszkowska A, Schmidt M, Trouillet JL, Leprince P, et al. Brain injury during venovenous extracorporeal membrane oxygenation. Intensive Care Med. 2016;42(5):897-907.
6. Abrams D, Grasselli G, Schmidt M, Mueller T, Brodie D. ECLS-associated infections in adults: what we know and what we don't yet know. Intensive Care Med. 2020;46(2):182-91.

7. Peek GJ, Mugford M, Tiruvoipati R, Wilson A, Allen E, Thalanany MM, Hibbert CL, Truesdale A, Clemens F, Cooper N, et al. Efficacy and economic assessment of conventional ventilatory support versus extracorporeal membrane oxygenation for severe adult respiratory failure (CESAR): a multicentre randomised controlled trial. Lancet. 2009;374(9698):1351-63.

8. Schmidt M, Zogheib E, Roze H, Repesse X, Lebreton G, Luyt CE, Trouillet $J$, Brechot N, Nieszkowska A, Dupont H, et al. The PRESERVE mortality risk score and analysis of long-term outcomes after extracorporeal membrane oxygenation for severe acute respiratory distress syndrome. Intensive Care Med. 2013;39(10):1704-13.

9. Wang ZY, LiT, Wang CT, Xu L, Gao XJ. Assessment of 1-year outcomes in survivors of severe acute respiratory distress syndrome receiving extracorporeal membrane oxygenation or mechanical ventilation: a prospective observational study. Chin Med J (Engl). 2017;130(10):1161-8.

10. Grasselli G, Scaravilli V, Tubiolo D, Russo R, Crimella F, Bichi F, Corinna Morlacchi L, Scotti E, Patrini L, Gattinoni L, et al. Quality of life and lung function in survivors of extracorporeal membrane oxygenation for acute respiratory distress syndrome. Anesthesiology. 2019;130(4):572-80.

11. Chen KH, Tsai FC, Tsai CS, Yeh SL, Weng LC, Yeh LC. Problems and health needs of adult extracorporeal membrane oxygenation patients following hospital discharge: a qualitative study. Heart Lung. 2016;45(2):147-53.

12. Force ADT, Ranieri VM, Rubenfeld GD, Thompson BT, Ferguson ND, Caldwell E, Fan E, Camporota L, Slutsky AS. Acute respiratory distress syndrome: the Berlin Definition. JAMA. 2012;307(23):2526-33.

13. Extracorporeal Life Support Organization (ELSO), Guidelines for Adult Respiratory Failure, August, V 1.4, 2017 https://www.elso.org/Portals/0/ ELSO\%20Guidelines\%20For\%20Adult\%20Respiratory\%20Failure\%201_4. pdf. Accessed 03 Feb 2020.

14. Tarlov AR, Ware JE Jr, Greenfield S, Nelson EC, Perrin E, Zubkoff M. The Medical Outcomes Study. An application of methods for monitoring the results of medical care. JAMA. 1989;262(7):925-30.

15. Jones PW, Quirk FH, Baveystock CM, Littlejohns P. A self-complete measure of health status for chronic airflow limitation. The St. George's Respiratory Questionnaire. Am Rev Respir Dis. 1992;145(6):1321-7.

16. Zigmond AS, Snaith RP. The hospital anxiety and depression scale. Acta Psychiatr Scand. 1983;67(6):361-70.

17. Hinz A, Brahler E. Normative values for the hospital anxiety and depression scale (HADS) in the general German population. J Psychosom Res. 2011;71(2):74-8.

18. Ellert U, Kurth BM. Health related quality of life in adults in Germany: results of the German Health Interview and Examination Survey for Adults (DEGS1). Bundesgesundheitsblatt Gesundheitsforschung Gesundheitsschutz. 2013;56(5-6):643-9.

19. Lutter Jl, Jorres RA, Kahnert K, Schwarzkopf L, Studnicka M, Karrasch S, Schulz H, Vogelmeier CF, Holle R, Group CS. Health-related quality of life associates with change in FEV1 in COPD: results from the COSYCONET cohort. BMC Pulm Med. 2020;20(1):148.

20. Ferrer M, Villasante C, Alonso J, Sobradillo V, Gabriel R, Vilagut G, Masa JF, Viejo JL, Jiménez-Ruiz CA, Miravitlles M. Interpretation of quality of life scores from the St George's Respiratory Questionnaire. Eur Respir J. 2002;19(3):405-13.

21. Dowdy DW, Eid MP, Dennison CR, Mendez-Tellez PA, Herridge MS, Guallar E, Pronovost PJ, Needham DM. Quality of life after acute respiratory distress syndrome: a meta-analysis. Intensive Care Med. 2006;32(8):1115-24.

22. Herridge MS, Cheung AM, Tansey CM, Matte-Martyn A, Diaz-Granados N, Al-Saidi F, Cooper AB, Guest CB, Mazer CD, Mehta S, et al. One-year outcomes in survivors of the acute respiratory distress syndrome. N Engl J Med. 2003;348(8):683-93.

23. Schmidt M, Bailey M, Sheldrake J, Hodgson C, Aubron C, Rycus PT, Scheinkestel C, Cooper DJ, Brodie D, Pellegrino V, et al. Predicting survival after extracorporeal membrane oxygenation for severe acute respiratory failure The Respiratory Extracorporeal Membrane Oxygenation Survival Prediction (RESP) score. Am J Respir Crit Care Med. 2014;189(11):1374-82.

24. Raith EP, Udy AA, Bailey M, McGloughlin S, Maclsaac C, Bellomo R, Pilcher DV. Australian, New Zealand Intensive Care Society Centre for O, Resource E: Prognostic accuracy of the SOFA score, SIRS criteria, and qSOFA score for in-hospital mortality among adults with suspected infection admitted to the intensive care unit. JAMA. 2017;317(3):290-300. 
25. Knaus WA, Draper EA, Wagner DP, Zimmerman JE. APACHE II: a severity of disease classification system. Crit Care Med. 1985;13(10):818-29.

26. Abrams D, Ferguson ND, Brochard L, Fan E, Mercat A, Combes A, Pellegrino V, Schmidt M, Slutsky AS, Brodie D. ECMO for ARDS: from salvage to standard of care? Lancet Respir Med. 2019;7(2):108-10.

27. Staudacher DL, Gold W, Biever PM, Bode C, Wengenmayer T. Early fluid resuscitation and volume therapy in venoarterial extracorporeal membrane oxygenation. J Crit Care. 2017;37:130-5.

28. Rilinger J, Zotzmann V, Bemtgen X, Schumacher C, Biever PM, Duerschmied D, Kaier K, Stachon P, von Zur MC, Zehender M, et al. Prone positioning in severe ARDS requiring extracorporeal membrane oxygenation. Crit Care. 2020;24(1):397.

29. Roch A, Hraiech S, Masson E, Grisoli D, Forel JM, Boucekine M, Morera P, Guervilly C, Adda M, Dizier S, et al. Outcome of acute respiratory distress syndrome patients treated with extracorporeal membrane oxygenation and brought to a referral center. Intensive Care Med. 2014;40(1):74-83.

30. Schmidt M, Pham T, Arcadipane A, Agerstrand C, Ohshimo S, Pellegrino V, Vuylsteke A, Guervilly C, McGuinness S, Pierard S, et al. Mechanical ventilation management during extracorporeal membrane oxygenation for acute respiratory distress syndrome. An international multicenter prospective cohort. Am J Respir Crit Care Med. 2019;200(8):1002-12.

31. Rilinger J, Zotzmann V, Bemtgen X, Rieg S, Biever PM, Duerschmied D, Pottgiesser T, Kaier K, Bode C, Staudacher DL et al. Influence of immunosuppression in patients with severe acute respiratory distress syndrome on veno-venous extracorporeal membrane oxygenation therapy. Artif Organs. 2021.

32. Sylvestre A, Adda M, Maltese F, Lannelongue A, Daviet F, Parzy G, Coiffard B, Roch A, Loundou A, Baumstarck K, et al. Long-term neurocognitive outcome is not worsened by of the use of venovenous ECMO in severe ARDS patients. Ann Intensive Care. 2019;9(1):82.

33. Harley O, Reynolds C, Nair P, Buscher H. Long-term survival, posttraumatic stress, and quality of life post extracorporeal membrane oxygenation. ASAIO J. 2020;66(8):909-14.

\section{Publisher's Note}

Springer Nature remains neutral with regard to jurisdictional claims in published maps and institutional affiliations.

Ready to submit your research? Choose BMC and benefit from:

- fast, convenient online submission

- thorough peer review by experienced researchers in your field

- rapid publication on acceptance

- support for research data, including large and complex data types

- gold Open Access which fosters wider collaboration and increased citations

- maximum visibility for your research: over $100 \mathrm{M}$ website views per year

At BMC, research is always in progress.

Learn more biomedcentral.com/submissions 